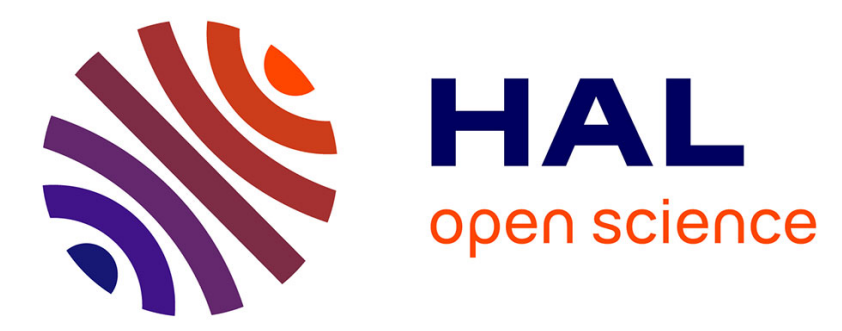

\title{
RRR of Copper Coating and Low Temperature Electrical Resistivity of Material for TTF Couplers
}

\author{
M. Fouaidy, N. Hammoudi
}

\section{To cite this version:}

M. Fouaidy, N. Hammoudi. RRR of Copper Coating and Low Temperature Electrical Resistivity of Material for TTF Couplers. 12th International Workshop on RF Superconductivity (SRF 2005), Jul 2005, Ithaca, United States. 2005. in2p3-00123410

\section{HAL Id: in2p3-00123410 https://hal.in2p3.fr/in2p3-00123410}

Submitted on 9 Jan 2007

HAL is a multi-disciplinary open access archive for the deposit and dissemination of scientific research documents, whether they are published or not. The documents may come from teaching and research institutions in France or abroad, or from public or private research centers.
L'archive ouverte pluridisciplinaire HAL, est destinée au dépôt et à la diffusion de documents scientifiques de niveau recherche, publiés ou non, émanant des établissements d'enseignement et de recherche français ou étrangers, des laboratoires publics ou privés. 


\title{
RRR OF COPPER COATING AND LOW TEMPERATURE ELECTRICAL RESISTIVITY OF MATERIAL FOR TTF COUPLERS
}

\author{
M. Fouaidy, N. Hammoudi, IPN Orsay, France
}

\begin{abstract}
In the framework of the R\&D program on the TTF III main RF coupler, IPN Orsay developed in close collaboration with LAL institute, a dedicated facility for the electrical characterization of different materials at low temperature. This apparatus was used for measuring the electrical resistivity versus temperature $(4.2 \mathrm{~K}-300 \mathrm{~K})$ of various samples produced in the industry. These tests were performed in order to compare the RRR of the samples, qualify and find the optimum parameters for the coating process. Seven flat samples were tested in a saturated liquid helium bath under $\sim 1013$ mbar pressure: measurements were performed on bare 316L samples, nickel coated 316L samples, and copper coated 316L samples with a nickel under layer. We investigated, in particular, the effect of vacuum annealing at $400^{\circ} \mathrm{C}$ on the RRR of the copper coating. Our experimental data are compared to previous measurements reported by other groups, and theoretical results (e.g. Gruneisen-Bloch equation) and a good agreement was found. Finally, the tested samples fulfil the TTF III coupler design parameters requirements in terms of heat loads to the refrigerator at $2 \mathrm{~K}, 4 \mathrm{~K}$ and $70 \mathrm{~K}$.
\end{abstract}

\section{INTRODUCTION}

The power coupler is a crucial component for operating Superconducting RF (SRF) cavities. The main function of this device is the efficient transfer, in matched condition, of the RF power from the source to the particles beam. This complex device operates in stringent conditions: 1) it should handle and transmit a high RF power $(\sim 250 \mathrm{~kW}$ $500 \mathrm{~kW}$ ) through a ceramic window, 2) it is an interface between warm parts of the accelerating cryomodule at room temperature $(\mathrm{T} \sim 300 \mathrm{~K})$ and cold parts at cryogenic temperatures (i.e. $\mathrm{T}<100 \mathrm{~K}$ ), 3 ) it is also an interface between atmospheric pressure in the wave guide operating at room temperature and ultrahigh vacuum $\left(<10^{-8} \mathrm{mbar}\right)$ in the SRF cavity. Due to such operating conditions, the RF power coupler should be carefully designed in order to achieve reliably the required performance. For a large superconducting linac such as TESLA (actually ILC: International Linear $\underline{\text { Collider) or }}$ XFEL [1-3], it is mandatory to minimize the cryogenic power needed for the machine. Consequently, the static and dynamic heat load contributions of the power coupler to the cryomodule must be kept as low as possible. In the framework of the CARE-SRF project WP7 supported by EU, LAL and DESY laboratories launched an R\&D program aimed at the development and fabrication in the industry of forty TTFIII power couplers [4-9]. In this program, the development of high performance copper coating for the different parts of the power coupler (e.g. inner conductor, outer conductor, bellows) is of prime importance for reducing the cryogenic thermal budget to the refrigerator operating at $\mathrm{a} T=2 \mathrm{~K}$.

\section{MAIN DESIGN PARAMETERS OF TTF3 COUPLER AND THERMAL SPECIFICATIONS}

The TTF III power coupler (Fig. 1) is of coaxial type with two cylindrical alumina windows: 1) a warm window, operating at $T \cong 300 \mathrm{~K}$, and located at the waveguide to coax transition (upper part), 2) a cold window, located at the lower part and thermally anchored to the infrared radiation shield at $\mathrm{T} \cong 70 \mathrm{~K}$.

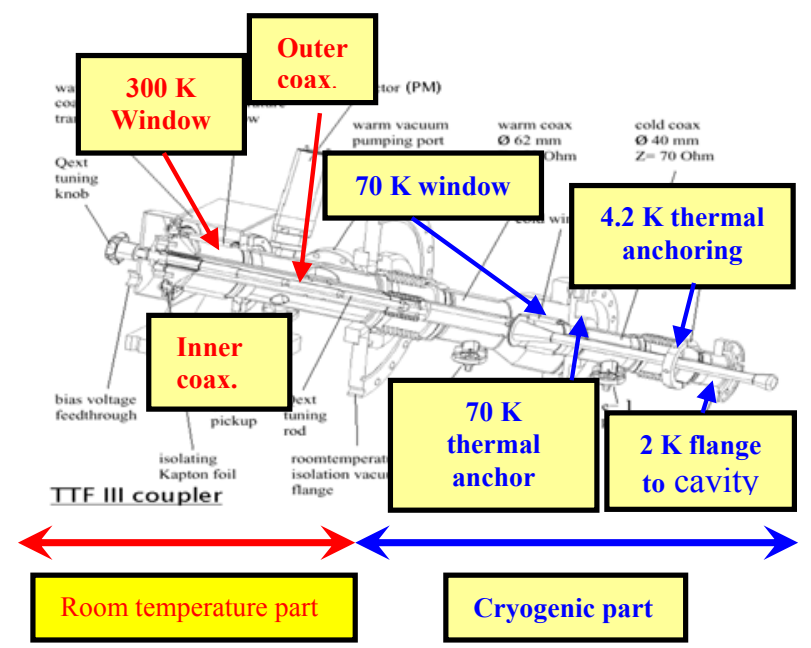

Fig. 1: Drawing of the TTF III power coupler

The inner and outer conductors are made of $316 \mathrm{~L}$ stainless steel with copper plating, while the antenna is made of OFE bulk copper. Furthermore, copper plated stainless steel bellows are used in order to avoid thermomechanical stresses due to differential thermal contractions between the different materials (e.g. $\mathrm{Nb}$ for cavity: $\Delta \mathrm{L} /\left.\mathrm{L}\right|_{4}{ }^{300}=-0.143 \%$, stainless steel for coupler: $\Delta \mathrm{L} /\left.\mathrm{L}\right|_{4}{ }^{300}=-0.3 \%, \mathrm{Cu}$ for coupler: $\Delta \mathrm{L} /\left.\mathrm{L}\right|_{4}{ }^{300}=-0.324 \%$, Ti for liquid helium tank: $\Delta \mathrm{L} /\left.\mathrm{L}\right|_{4} ^{300}=-0.151 \%$ ) during cool down of the cryomodule to cryogenic temperatures. Moreover, two thermal anchoring linked to infrared thermal radiations shields at $4.2 \mathrm{~K}$ and $70 \mathrm{~K}$ respectively allows the interception of the heat flux (solid conduction and RF losses due to Joule heating): their role is to 
reduce the heat load to the cavity at $\mathrm{T}=2 \mathrm{~K}$. Furthermore, the TTF III power coupler should handle and transmit efficiently a high RF power in pulsed mode (e.g. peak RF power: $250 \mathrm{~kW}$, average power of $3.2 \mathrm{~kW}$ for a pulse length $\tau_{\mathrm{P}}=1300 \mathrm{~ms}$ at a repetition rate of $10 \mathrm{~Hz}$ ) to the electrons or positrons beam with minimum heat loads to the different cooling circuits of the refrigerator (e.g. $\mathrm{T}=2 \mathrm{~K}, \mathrm{~T}=4.2 \mathrm{~K}$ and $\mathrm{T}=70 \mathrm{~K})$. The main design parameters, which have a major effect on the thermal performance of the power coupler and the cryomodule, are illustrated in Table 1.

Table 1: Main design parameters of TTF III coupler and thermal specifications

\begin{tabular}{|c|c|}
\hline Parameter & Specification \\
\hline Frequency (MHz) & 1300 \\
\hline Operating mode & $\begin{array}{c}\text { Pulsed, total pulse length: } \\
\tau_{\mathrm{P}}=1300 \mu \mathrm{s}, \text { rise time } \tau_{\mathrm{R}}=500 \mu \mathrm{s}, \\
\text { flat top with beam } \tau_{\mathrm{FTop}}=800 \mu \mathrm{s}\end{array}$ \\
\hline $\begin{array}{c}\begin{array}{c}\text { Heat load @ } 2 \mathrm{~K} \\
(\mathrm{~mW})\end{array} \\
\end{array}$ & 60 \\
\hline $\begin{array}{c}\text { Heat load@ @ K } \\
\text { (mW) }\end{array}$ & 500 \\
\hline $\begin{array}{c}\text { Heat load@ } 970 \mathrm{~K} \\
\text { (W) }\end{array}$ & 6 \\
\hline $\begin{array}{c}\text { Peak RF power } \\
(\mathrm{kW})\end{array}$ & 250 \\
\hline $\begin{array}{l}\text { Average RF } \\
\text { power }(\mathrm{kW})\end{array}$ & 3.2 \\
\hline $\begin{array}{c}\text { Repetition rate } \\
(\mathrm{Hz})\end{array}$ & 10 \\
\hline
\end{tabular}

\section{Copper coating specifications for the TTF-3 couplers}

Among others items, the copper coating of the coupler is an important task in order to achieve the required RF and thermal performance. The optimum values of the coating characteristics (e.g. thickness $\mathrm{e}_{\mathrm{Cu}}$, purity, low hydrogen content, residual electrical resistivity $\rho_{R}$, low temperature thermal conductivity $\mathrm{k}_{\mathrm{Cu}}(\mathrm{T})$, low temperature surface resistance $R_{S}(T)$, adhesion on stainless steel substrate and surface roughness $\mathrm{R}_{\mathrm{a}}$ ) are a compromise between several criteria. More precisely, the heat load $\mathrm{Q}_{\text {Cold }}$ to the $2 \mathrm{~K}$ circuit should be low and have two contributions, namely the static part $\mathrm{Q}_{\text {cond }}$ and the dynamic part $\mathrm{Q}_{\mathrm{RF}}$. The static part is due to solid conduction and is simply given by the expression:

$$
Q_{\text {cond }}=\frac{A_{C u}}{L_{\text {eff }}} \int_{T C}^{T H} k_{C u}(T) \cdot d T
$$

With:

- $\mathrm{A}_{\mathrm{Cu}}$ : area of the copper coating in the heat flow direction $\left(\mathrm{A}_{\mathrm{Cu}} \cong \pi \cdot \mathrm{D}_{\mathrm{eff}} \cdot \mathrm{e}_{\mathrm{Cu}}\right)$,
- $D_{\text {eff }}$ : effective diameter of the coated substrate (pipe or bellow),

- $\mathrm{L}_{\text {eff }}$ : effective length of the conduction thermal path,

- TC cold temperature,

- $\quad$ TH hot temperature.

The dynamic part $\mathrm{Q}_{\mathrm{RF}}$ is due to Joule heating of the copper coating by the RF surface magnetic field $\mathrm{H}_{\mathrm{S}}$ :

$$
Q_{R F}=\frac{1}{2} \iint_{S C u} R_{S}(T) \cdot H_{S}^{2} d S
$$

From the above relation ship (1), the conduction heat flux $\mathrm{Q}_{\text {Cold }}$ is proportional to both the thickness and the mean thermal conductivity of the copper coating $\left(\mathrm{Q}_{\text {cond }} \propto\right.$ $\left.\mathrm{A}_{\mathrm{Cu}} \cdot \mathrm{k}_{\mathrm{Cu}} \propto \mathrm{e}_{\mathrm{Cu}} \cdot \mathrm{k}_{\mathrm{Cu}}\right)$. Then to reduce $\mathrm{Q}_{\mathrm{Cold}}, \mathrm{k}_{\mathrm{Cu}}$ should be lowered (i.e. the purity of the copper should be low) as well as its thickness. On the contrary, to reduce the RF losses $\mathrm{Q}_{\mathrm{RF}}, \mathrm{R}_{\mathrm{S}}(\mathrm{T})$ should be decreased: 1) in the normal skin effect regime, the low temperature surface resistance $\mathrm{R}_{\mathrm{S} 0}$ is proportional to the square root of the residual DC resistivity $\rho_{R}\left(\right.$ e.g. $\left.R_{S 0} \propto\left(\rho_{R}\right)^{0.5}\right)$, hence $\rho_{R}$ should be low or namely copper purity should be high, 2) in the anomalous skin effect regime, the low temperature surface resistance $\mathrm{R}_{\mathrm{S} 0}$ is independent of copper purity or $\rho_{\mathrm{R}}$ (for copper at TESLA frequency $\mathrm{f}=1300 \mathrm{MHz}$, $\mathrm{R}_{\mathrm{S} 0}=1.3 \mathrm{~m} \Omega$ ). Now it is clear that the two previous criteria are contradictory: more precisely to reduce $\mathrm{Q}_{\text {cond }}$ (respectively $\mathrm{Q}_{\mathrm{RF}}$ ) we should use low purity (respectively high purity) copper coating. As these two criteria go to reverse direction, there is an optimum value of $\rho_{R}$ or

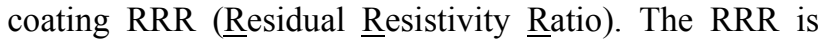
defined as the ratio between electrical resistivity of the material $\rho(\mathrm{T}=273 \mathrm{~K})$ at the ice point and the residual electrical resistivity $\rho_{R}$ measured at the liquid helium normal boiling point $(\mathrm{T}=4.22 \mathrm{~K})$ :

$$
R R R=\frac{\rho(T=273 K)}{\rho_{R}}
$$

Furthermore, the high temperature (i.e. $\mathrm{T} \cong 300 \mathrm{~K}$ ) electrical resistivity is weakly dependent on the material purity [10]. Consequently, we adapted through this paper the following expression of RRR:

$$
R R R \cong \frac{\rho(T=300 K)}{\rho_{R}}
$$

In the above expression (3b), the room temperature resistivity $\rho(T=300 \mathrm{~K})$ is used instead of the resistivity at ice point $\rho(T=273 K)$.

The following specifications and preparation procedure of the copper coatings are needed to achieve reliably the required RF and thermal performance (Table 1) of the TTF III power coupler:

1) Copper coated stainless steel is of austenitic grade AISI 316L (EN 1.4435), 
2) Stainless steel parts are Hydrogen degassed at $950^{\circ} \mathrm{C}$ for 2 hours,

3) Thicknesses are respectively $30 \mu \mathrm{m} \pm 10 \mu \mathrm{m}$ for the Inner Conductor (IC) and $10 \mu \mathrm{m} \pm 5 \mu \mathrm{m}$ for the Outer Conductor (OC) copper coatings,

4) Low hydrogen content,

5) Ni flash under layer thickness $\leq 1 \mu \mathrm{m}$

6) Electrical resistivity: $R R R \geq 30$ after baking at $400^{\circ} \mathrm{C}$ during $1 \mathrm{~h}$ in a vacuum furnace.

The effect of the copper coating RRR on the heat loads, at cryogenic temperature for the three thermal intercepts, was computed previously [11] at an average RF power of $10 \mathrm{~kW}$ leading to the results summarized in Table 2 . These results clearly show that a RRR of the copper coating higher than 30 fulfils the required thermal performance at $2 \mathrm{~K}$ and $4 \mathrm{~K}$ with a sufficient safety margin. Note that the heat loads are nearly proportional to the average RF power in the coupler. It should be stressed that the values of skin depth $\delta_{\mathrm{Cu}}$ (e.g. normal skin effect regime or anomalous skin effect regime), in which RF current is concentrated on the external surface of the coating during coupler operation at $\mathrm{f}=1300 \mathrm{MHz}$, are lower than $2 \mu \mathrm{m}$ for $2 \mathrm{~K} \leq \mathrm{T} \leq 300 \mathrm{~K}$ and copper RRR in the range10-100. Consequently, there is no RF current in the stainless steel substrate of the coupler components. Further, this value of $\delta_{\mathrm{Cu}}$ is at least 5 times lower than the minimum copper coating thickness.

Table 2: Effect of the copper coating RRR on the heat loads at cryogenic temperature for the three thermal intercepts- Average RF power of $10 \mathrm{~kW}$ [11]

\begin{tabular}{|c|c|c|c|c|c|}
\hline $\begin{array}{c}\text { Thick. } \\
(\mu \mathrm{m})\end{array}$ & Conduc. & RRR & $\begin{array}{c}\text { Load @2K } \\
\text { IC\&OC } \\
(\mathrm{mW})\end{array}$ & $\begin{array}{c}\text { Load @ 4K } \\
\text { IC\&OC } \\
(\mathrm{mW})\end{array}$ & $\begin{array}{c}\text { Load @ 70 K } \\
(\mathrm{W})\end{array}$ \\
\hline \hline 30 & IC & 10 & & & 10. \\
\hline \hline 10 & OC & 10 & 110 & 680 & 3.6 \\
\hline \hline 30 & IC & 100 & & & 9.7 \\
\hline 10 & OC & 100 & 130 & 730 & 3.1 \\
\hline
\end{tabular}

\section{COPPER COATING TECHNIQUE AND ROOM TEMPERATURE CHARACTERIZATION OF SAMPLES}

Two main techniques [12] could be used for coating stainless substrate with high purity copper: a) electrolytic deposition, b) magnetron sputtering. We decided to use the first method because, as compared to the second one this technique, it allows the production of high material performance in much easier manner. Briefly, the electrolytic coating process is performed in bath which contains typically the following impurities:
a) Chromium: $0.04 \mathrm{ppm}$,
b) Cobalt $<0.04 \mathrm{ppm}$ (detection limit),
c) Iron: $21.8 \mathrm{ppm}$,
d) Manganese: $0.01 \mathrm{ppm}$ (detection limit).

Note that the copper plating process of the samples and coupler parts was done in the industry. As the details of the process are considered to be proprietary of the industry, they could not be discussed in the present paper.

\section{Copper coating thickness measurement}

Non destructive measurements of thickness profiles were performed by X-Ray fluorescence method. Fischerscope ${ }^{\circledR}$ XRAY XDL device was used for this purpose. Five copper coated samples with a specified thickness $\mathrm{e}_{\mathrm{Cu}}=30 \mu \mathrm{m}$ were tested (Fig.2). This histogram shows that: a) the mean value of the coating thickness is $\left\langle\mathrm{e}_{\mathrm{Cu}}\right\rangle=33.68 \mu \mathrm{m}$ with a standard deviation $\sigma_{\mathrm{eCu}}=4.3$ $\mu \mathrm{m}$ and a range of $10.3 \mu \mathrm{m}, \mathrm{b}) \sigma_{\mathrm{eCu}}$ is within the specified

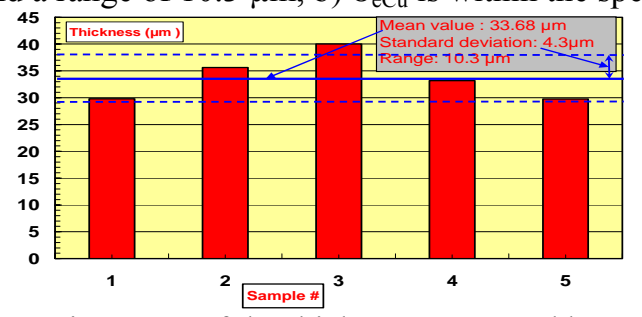

Fig. 2: Histogram of the thickness measured by X-Ray fluorescence.

tolerance of $\pm 20 \%$ (i.e. $\pm 6 \mu \mathrm{m}$ ), c) out of the five samples tested, only the sample \#3 is outside the specified range. Moreover, the micrographs showing the copper coating thickness distribution in the bellows is presented in Fig.3. The measured values $28 \mu \mathrm{m}-34 \mu \mathrm{m}$ are well in the specification range $(30 \mu \mathrm{m} \pm 10 \mu \mathrm{m})$.

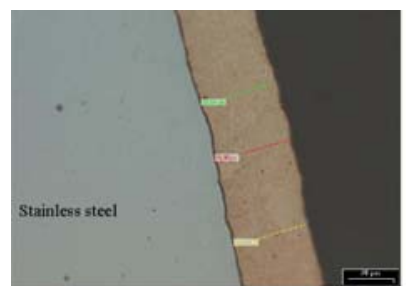

Fig. 3: Copper coating thickness distribution in some locations of the small bellow.

\section{Copper coating parts of TTF3 coupler}

The copper coating characteristics produced in the industry achieved the required properties, so we decided to coat the different parts of the TTF3 coupler (Fig.4).

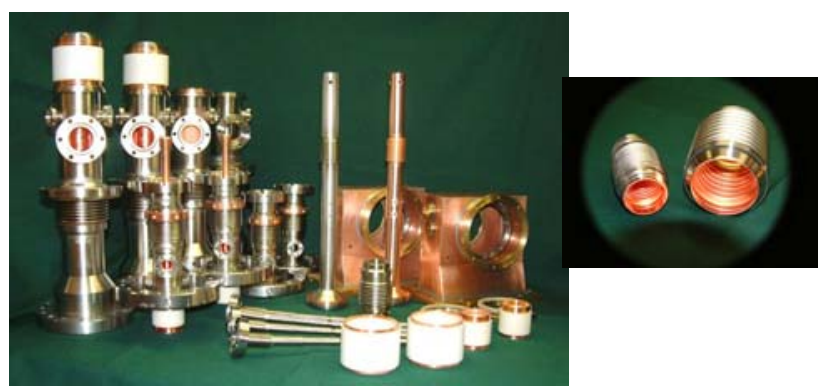

Fig. 4: Photographs of the different copper-plated parts of TTF3 coupler 


\section{ELECTRICAL RESISTIVITY AND RRR MEASUREMENT}

\section{Experimental set-up and procedure}

The measurements were performed using the standard DC four probes method (Fig. 5). The electrodes are clamped to the flat test sample by means of copperberyllium springs: the resulting contact pressure between

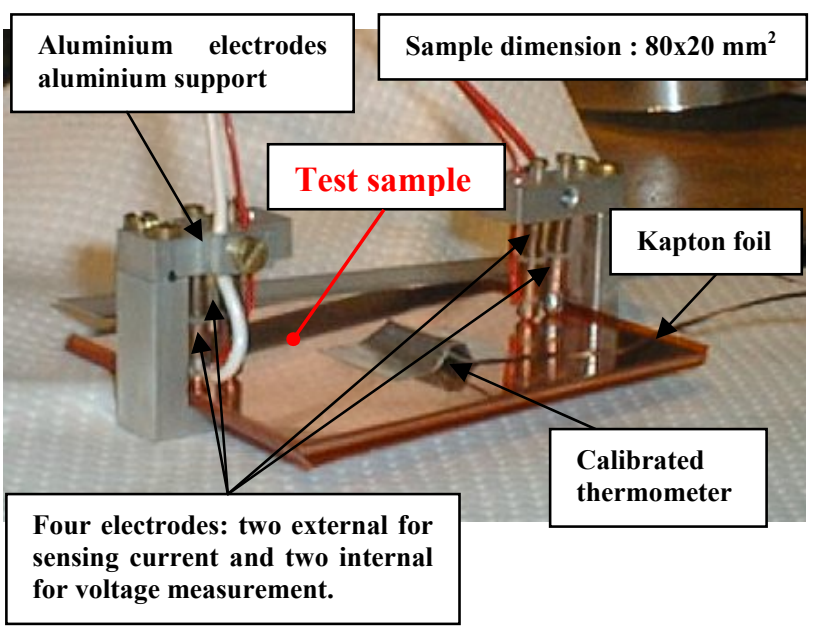

Fig. 5: A) Double side copper plated (30 $\mu \mathrm{m} /$ side) $316 \mathrm{~L}$ type stainless steel sample.

the electrodes tips and the sample is $\sim 12$ Bars. A Kapton foil of $\sim 0.1 \mathrm{~mm}$ thickness, sandwiched between the sample and electrodes support, allows their electrical insulation from the sample. Finally the distance between the voltage electrodes is $\sim 60 \mathrm{~mm}$. The test sample, which is equipped with a calibrated [13] Cernox thermometer $(\mathrm{T}=1.6 \mathrm{~K}-300 \mathrm{~K})$, is then immersed in a saturated liquid helium bath (Pressure: $\mathrm{P}=100 \mathrm{kPa}, \mathrm{T}=4.2 \mathrm{~K}$ ). The sensing current, which is delivered by a precise standard $\mathrm{DC}$ voltage supply and set to a value close to $1.5 \mathrm{~A}$, is maintained constant during the whole test and on-line measured via the voltage drop across a precision resistor $\left(\mathrm{R}=1 \Omega, \Delta \mathrm{R} / \mathrm{R} \sim 10^{-4}\right)$.

The different steps of the experiment are the following: a) Perform 10 measurements at $\mathrm{T}=4.2 \mathrm{~K}$, each measurement consisting of 15 dual scans in the direct $(+\mathrm{V})$ and reverse direction $(-\mathrm{V})$,

b) Vaporize the liquid helium using a bath heater,

c) Heat the sample in a controlled way to maintain it at a given constant temperature $\mathrm{T}$ in the range $4.2 \mathrm{~K}-300 \mathrm{~K}$,

d) Once $\mathrm{T}$ is stable, perform 10 measurements (5 to 10 dual scans),

e) This process (c-d) is repeated as function of temperature from $4.2 \mathrm{~K}$ to $300 \mathrm{~K}$.

Note that, as the measured signal is very small (i.e. 45 $\mu \mathrm{V}-450 \mu \mathrm{V})$, the change of the sensing current direction is mandatory in order to eliminate parasitic thermal voltages.

\section{Results and discussion}

Due to the very low thickness $(\sim 10-30 \mu \mathrm{m})$ of the copper coating and the electrical contact type between sample and measuring electrodes (no soldering, contact by pressure), it is not possible to measure directly the resistance of the copper coating alone and especially at cryogenic temperatures: the sample could be broken or damaged. Moreover, the coating electrical resistivity should be measured in real operating conditions (i.e. with the stainless steel substrate): the coating thermomechanical stress has an influence on the electrical resistivity. Consequently, the measurement method is by comparison: we measured both coated and uncoated samples including those with only the nickel under layer coating, which is sandwiched between the stainless steel substrate and the copper coating. Further, in our knowledge, only few precise results of the electrical resistivity of Stainless Steel (SS) at low temperature were previously published; it is then interesting to get such data. Six coated and uncoated samples (Table 3) were tested. Notice that for all the coated samples, the thickness of the nickel under layer is $1-2 \mu \mathrm{m}$. The sample \#1was tested twice: a) as received, b) after annealing at $400^{\circ} \mathrm{C}$ in a vacuum furnace. The sample \#4 was also tested twice: a) as received, b) after chemical removal of the nickel under layer.

Table 3: Description of the tested samples

\begin{tabular}{|c|c|}
\hline Sample \# & Description \\
\hline 1 as received & $\begin{array}{c}\mathrm{SS}+\mathrm{Ni} \text { under layer coating }+ \\
\text { copper coating: double sided } \\
(30 \mu \mathrm{m} / \mathrm{side})\end{array}$ \\
\hline $\begin{array}{c}1 \text { after vacuum } \\
\text { annealing }\left(400^{\circ} \mathrm{C} \text {, }\right. \\
1 \mathrm{~h} 00)\end{array}$ & $\begin{array}{c}\mathrm{SS}+\text { double sided copper coating } \\
(30 \mu \mathrm{m} / \mathrm{side})\end{array}$ \\
\hline 3 & Bare 316L Stainless Steel \\
\hline 4 & $\begin{array}{c}\mathrm{SS}+\text { double sided Ni under layer } \\
\text { coating }\end{array}$ \\
\hline $4 \mathrm{~A}$ & $\begin{array}{c}\text { Sample \#4 after chemical removal } \\
\text { of Ni }\end{array}$ \\
\hline 5 & $\begin{array}{c}\mathrm{SS}+\mathrm{Ni} \text { under layer coating }+ \\
\text { copper coating: double sided } \\
(33 \mu \mathrm{m} / \mathrm{side})\end{array}$ \\
\hline 6 & $\begin{array}{c}\mathrm{SS}+\mathrm{Ni} \text { under layer coating }+ \\
\text { copper coating: double sided } \\
(33 \mu \mathrm{m} / \mathrm{side})\end{array}$ \\
\hline
\end{tabular}

The histogram of ten measurements of the electrical resistance of the copper plated sample \#1 $\mathrm{R}_{\text {Samp.1 }}$ at $\mathrm{T}=4.2 \mathrm{~K}$ is shown in Fig. 6. These data lead to a mean value of the sample resistance $R_{\text {Samp. } 1}=31.8 \mu \Omega$, with a relative standard deviation $\sim 5.10^{-3}$ and a range $\Delta \mathrm{R}_{\text {Samp.1 }}=0.51 \mu \Omega$. Moreover, the variations of the sample resistance with temperature are presented in Fig. 7. As expected, the data show the well-known monotonic and strong decrease of $\mathrm{R}_{\text {Samp. } 1}$ with $\mathrm{T}$ from $285 \mu \Omega$ at $286 \mathrm{~K}$ 
down to $31.8 \mu \Omega$ at $4.2 \mathrm{~K}$ : this behaviour is typical of medium and high purity metals [10].

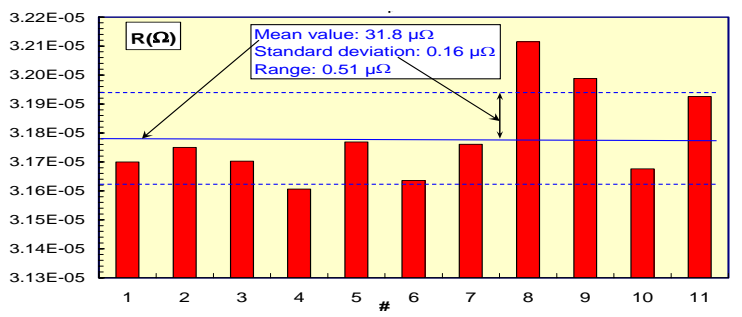

Fig. 6: Electrical resistance of sample $\# 1$ at $\mathrm{T}=4.2 \mathrm{~K}$.

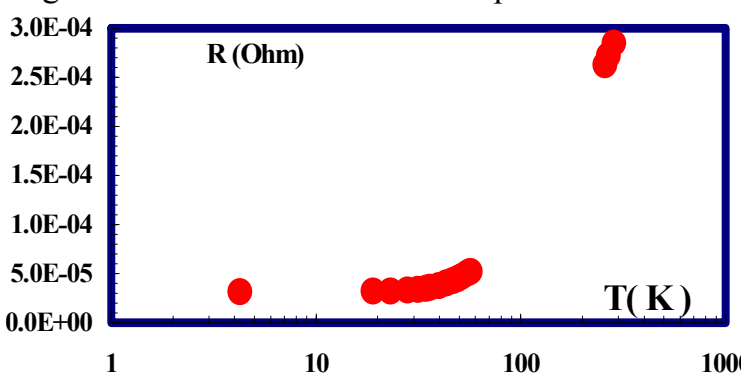

Fig. 7: Electrical resistance of sample \#1 versus temperature.

Furthermore, the results of Fig. 7 clearly show that the overall electrical conductance $1 / R_{\text {sample }}$ of the sample is dominated by the conductance of the copper coating 2. $\mathrm{e}_{\mathrm{Cu}} / \rho_{\mathrm{Cu}}$ : at $\mathrm{T}=4.2 \mathrm{~K}, \rho_{\mathrm{Cu}}$ is more than factor 300 lower than the electrical resistivity of stainless steel $\rho_{\mathrm{SS}}$. More precisely: a) for $\mathrm{RRR}=9.6$ copper, $\rho_{\mathrm{Cu}}=1.63510^{-8} \Omega . \mathrm{m}$ (a) $300 \mathrm{~K}$ and $\rho_{\mathrm{Cu}}=1.7110^{-9} \Omega . \mathrm{m}$ at $\mathrm{T}=4.2 \mathrm{~K}, \mathrm{~b}$ ) for $\mathrm{RRR}=27$ copper, $\rho_{\mathrm{Cu}}=1.5410^{-8} \Omega . \mathrm{m}$ at $\mathrm{T}=300 \mathrm{~K}$ and $\rho_{\mathrm{Cu}}=5.710^{-10} \Omega . \mathrm{m}$ at $\mathrm{T}=4.2 \mathrm{~K}, \mathrm{c}$ ) for stainless steel, $\rho_{\mathrm{SS}}=0.7810^{-6} \Omega . \mathrm{m} @ 300 \mathrm{~K}$ and $\rho_{\mathrm{SS}}=0.5310^{-6} \Omega . \mathrm{m}$ at $\mathrm{T}=4.2 \mathrm{~K}$.

The variations of the electrical resistivity as function of the temperature for $316 \mathrm{~L}$ stainless steel are illustrated in Fig. 8. This curve was simply deduced from the measurements of the sample resistance $\mathrm{R}_{\text {sample }}$ according to the well-known expression:

$$
\rho_{S S}=\frac{l \cdot e_{S S} \cdot R_{\text {Sample }}}{L}
$$

Where:

- $\quad$ L, 1 and $e_{S S}$ are respectively the distance between the voltage electrodes, the sample width and thickness.

From the above relationship, it is straightforward to derive the expression of the uncertainty on the stainless steel electrical resistivity:

$$
\frac{\Delta \rho_{S S}}{\rho_{S S}}=\frac{\Delta R_{\text {sample }}}{R_{\text {sample }}}+\frac{\Delta e_{S S}}{e_{S S}}+\frac{\Delta l}{l}+\frac{\Delta L}{L}
$$

By introducing the different contributions in the above relationship we obtained an uncertainty $\Delta \rho_{\mathrm{SS}} / \rho_{\mathrm{SS}}=6 \%$.
This value is close to the observed difference $( \pm 8 \%)$ between the two stainless steel samples \#3 and \#4A we tested. The remaining deviation of $2 \%$ could be attributed to variations in the chemical composition from sample to sample. Moreover, our experimental data are in a very good agreement with earlier results obtained by Clark et al. [14] who tested four different samples. Note that Clark performed the measurements at only five fixed thermometric points, namely in ice-liquid water mixture, normal boiling points of nitrogen, hydrogen and helium respectively.

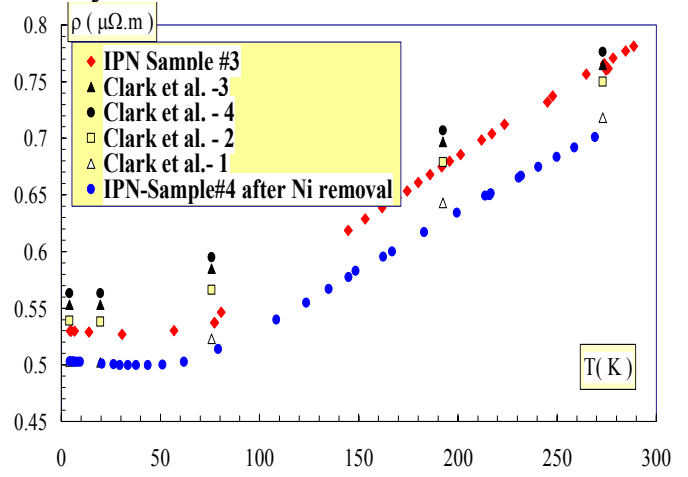

Fig. 8: Electrical resistivity of 316L type stainless steel versus temperature: comparison of IPN Orsay experimental data with previous results.

The double side coated sample could be simply modelled as a network of five resistances in parallel: one for stainless steel substrate, two for the copper coating and two for the nickel under layer. The equivalent electrical conductance of the sample is simply:

$$
\frac{1}{R_{\text {Sample }}}=\frac{l}{L}\left(\frac{e_{S S}}{\rho_{S S}}+\frac{2 \cdot e_{C u}}{\rho_{C u}}+\frac{2 \cdot e_{N i}}{\rho_{N i}}\right)
$$

Where:

- $\quad \mathrm{e}_{\mathrm{Ni}}$ and $\rho_{\mathrm{Ni}}$ are respectively the thickness and the electrical resistivity of the nickel under layer.

The results obtained with samples \#3, \# 4 and \#5 are illustrated in Fig.9.

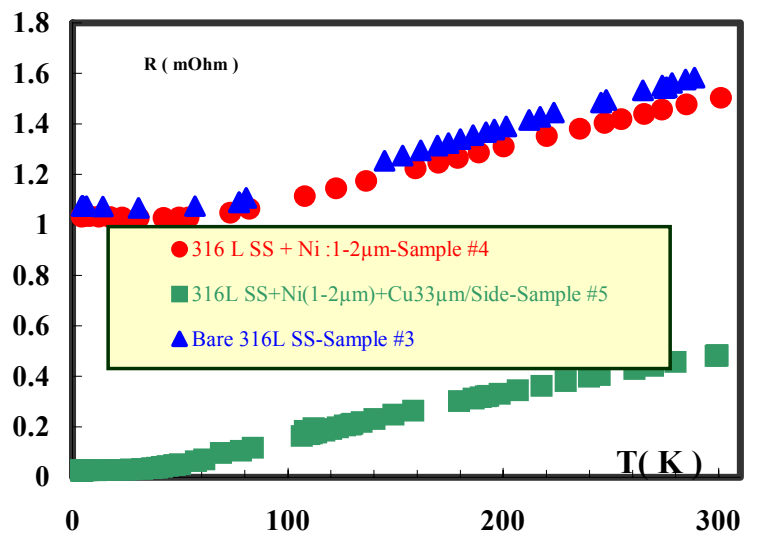

Fig.9: Effect of Ni under layer: bare stainless steel versus $\mathrm{Ni}$ and $\mathrm{Ni} \& \mathrm{Cu}$ coated samples. 
These data clearly show the effect of nickel and copper on the electrical resistance of the sample. Note that the contribution of the nickel layer to the overall resistance of the sample, thought is measurable, is small as compared to that of copper. This is simply due to 2 factors: a) the very low thickness $(\sim 1.5 \mu \mathrm{m})$ of $\mathrm{Ni}$ as compared to that of $\mathrm{Cu}(\sim 30 \mu \mathrm{m})$ and substrate $(\sim 1.5 \mu \mathrm{mm})$, b) the high electrical resistivity of the nickel sub layer, which is probably dirty or alloyed.

Using equation 6 and the data of Fig.9 we have deduced the electrical resistivity of the copper coating (Fig. 10).

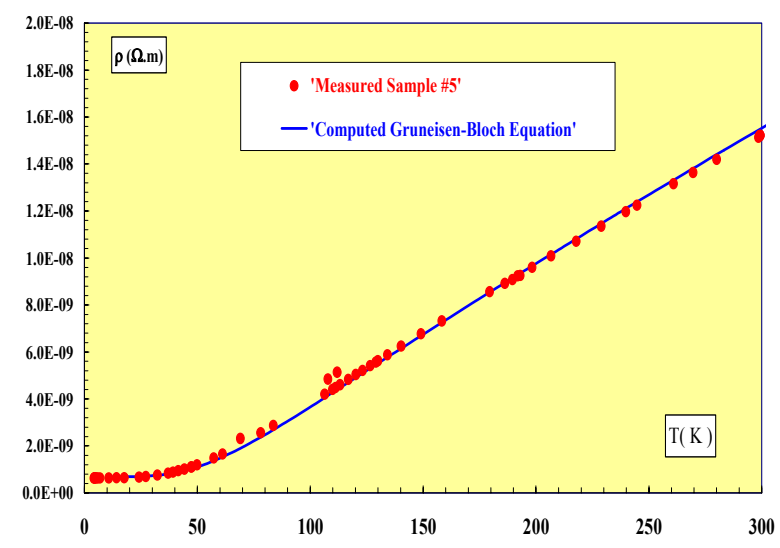

Fig. 10: Electrical resistivity of the copper coating

The estimated error for $\rho_{\mathrm{Cu}}$ is $12 \%$ at $\mathrm{T}=4.2 \mathrm{~K}$. Our experimental data are compared to the theoretical curve $\rho_{\mathrm{Cu}}$ versus $\mathrm{T}$. This theoretical curve was calculated assuming the Matthiesen's rule:

$$
\rho_{C u}(T)=\rho_{i}(T)+\rho_{R}
$$

Where the intrinsic electrical resistivity $\rho_{\mathrm{i}}(\mathrm{T})$ of ideally pure copper material, which is due to thermal scattering (e.g. simple free-electron model of a Debye solid), is given by the well-known Gruneisen-Bloch equation [15] :

$$
\rho_{i}(T)=4.226\left(\frac{T}{\theta}\right)^{5} \cdot \rho_{\theta}(T) \cdot J_{5}\left(\frac{\theta}{T}\right)
$$

The characteristic temperature $\theta$ of the solid phonons spectrum depends on the material. The function $J_{5}$ is the integral expressed as:

$$
J_{5}\left(\frac{\theta}{T}\right)=\int_{0}^{\theta / T} \frac{x^{5} d x}{\left(e^{x}-1\right)\left(1-e^{-x}\right)}
$$

For the copper, the theoretical Debye temperature is $\theta_{\mathrm{D}}=310 \mathrm{~K}$. However, the experimental values reported for $\theta_{\mathrm{D}}$ depends on $\mathrm{T}$, especially for $\mathrm{T}<200 \mathrm{~K}$ : they are in the range $310 \mathrm{~K}-350 \mathrm{~K}$ [15]. The best fit to our experimental data, according to the Gruneisen-Bloch equation, was obtained with $\theta=340 \mathrm{~K}$ and copper $\mathrm{RRR}=25$. Further the resolution of the electronics used for the tests is not sufficient for the precise measurement of the electrical resistivity of the nickel sub layer. Consequently we have to assume reasonable values of this parameter in order to deduce the RRR of copper coating from our experimental data. The summary of RRR measurements for all the samples tested are illustrated in Table 4: the estimated error on RRR measurement is $24 \%$.

For the samples without any heat treatment (i.e. as received), the RRR of $\mathrm{Cu}$ coating are in the range 20-46 if we use a realistic value of $\mathrm{Ni} R R R$ (i.e. RRRNi 1). Moreover the RRR data of sample \#1 are in good agreement with the Gruneisen-Bloch equation: the measured value of copper coating $(R R R=20)$ is consistent with that given by the theory $(R R R=25)$.

Table 4: Summary of copper coating RRR results

\begin{tabular}{|c|c|c|c|}
\hline Sample & $\begin{array}{c}\text { Ni effect } \\
\text { neglected }\end{array}$ & RRRNi =1 & $\begin{array}{c}\text { RRRNi } \\
=300\end{array}$ \\
\hline \#1 As received & 19.8 & 20.4 & 11.2 \\
\hline $\begin{array}{c}\text { \#1 Vacuum } \\
\text { Annealed@ } \\
400^{\circ} \text { during } \\
\text { h00 }\end{array}$ & 113 & 117 & 107 \\
\hline \#5 As received & 23.7 & 24 & 21 \\
\hline \#6 As received & 45.5 & 45.9 & 43 \\
\hline
\end{tabular}

The team of Benvenuti studied the properties of copper coatings developed for the main couplers of LEP2 accelerator [12]. Their data concerning as produced (i.e. before heat treatment) copper coatings are respectively $R R R=90$ (pyrophosphate electrolytic bath) and $R R R=110$ (sulphate electrolytic bath) for electroplated samples of $30 \mu \mathrm{m} \mathrm{Cu}$ thickness: the higher RRR obtained with sulphate electrolytic bath is attributed to the larger grain size observed [12]. Moreover, the values measured by Benvenuti are 2 to 5 time higher than our data. However, as compared to data obtained at DESY, our RRR results are much higher: Singer et al. [16] measured RRR $\sim 15$ for non annealed 5- $10 \mu \mathrm{m}$ thick copper coatings.

Furthermore, the vacuum annealing at $400^{\circ} \mathrm{C}$ during one hour increases the RRR of copper coating by a factor $\sim 6$. This improvement by a factor of 6 is two times higher than that observed by Benvenuti who measured $R R R=300$ for an electroplated sample (initial $R R R=110$ ) after vacuum annealing at $400^{\circ} \mathrm{C}$ during 2 hours. The significant improvement of the RRR of the copper is mainly due to 2 factors: a) the re-crystallization and the resulting increase of grain size by annealing observed by microstructure analysis [16], b) out gassing. Note that the optimum vacuum annealing temperature is in the range $350{ }^{\circ} \mathrm{C}-400{ }^{\circ} \mathrm{C}$ for a baking duration $\tau_{\text {annealing }}=1-2$ hours. It should be stressed that to keep the diffusion depth $\delta_{\text {Diff }}$ of nickel or iron into copper very much lower than copper thickness, the annealing temperature should be lower than $400^{\circ} \mathrm{C}[16]$. More precisely, $\delta_{\text {Diff }} \propto\left(\tau_{\text {annealing. }} \mathrm{D}\right)^{1 / 2}$. The 
diffusion coefficient $\mathrm{D}$ depends on the absolute annealing temperature $\mathrm{T}_{\text {annealing }}$ (e.g. $\mathrm{D} \sim \exp \left(-\Delta \mathrm{H} / \mathrm{R} \cdot \mathrm{T}_{\text {annealing }}\right)$ ) where $\Delta H$, and $R$ are respectively the enthalpy of the diffusion process and $\mathrm{R}$ the gas constant.

\section{CONCLUSION}

In the frame of the CARE-SRF project WP7 R\&D program aimed at development and fabrication in the industry of thirty TTF III power couplers, we designed an apparatus dedicated to the measurement of the electrical resistivity of materials at low temperatures. The electrical resistivity of different materials (stainless steel, $\mathrm{Cu}$ coating) were measured in the range $4.2 \mathrm{~K}-300 \mathrm{~K}$. The RRR of $\mathrm{Cu}$ coating was deduced from these data: 1) for as received samples the RRR values are in the range 20-46, 2) the vacuum annealing at $400^{\circ} \mathrm{C}$ during one hour increases the RRR of copper coating by a factor $\sim 6$. Moreover, our electrical resistivity data are compared to previous results reported by other groups for stainless and a good agreement was found. Our measured electrical resistivity data versus temperature for copper coatings are well fitted by the theoretical Gruneisen-Bloch equation. Finally, the tested samples fulfil the TTF III design parameters requirements in terms of heat loads to the refrigerator at $2 \mathrm{~K}, 4 \mathrm{~K}$, and $70 \mathrm{~K}$.

\section{ACKNOWLEDGEMENTS}

We acknowledge the support of the European Community-Research Infrastructure Activity under the FP6 "Structuring the European Research Area" programme (CARE, contract number RII3-CT-2003506395).

\section{REFERENCES}

[1] J. Andruszkow et al., "TESLA The Superconducting Electron-Positron Linear Collider with an Integrated X-Ray Laser Laboratory- Technical Design Report, Part II : The Accelerator", Editors R.Brinkmann, K. Flöttmann, J.Rossbach, P. Schmüser, N. Walker, H. Weise, March 2001.

[2] B. Aune et al., 'Superconducting TESLA cavities', Phys. Rev. Special Topics- Accelerators and Beams, Vol.3, pp. 092001-1, 092001-25, 2000.

[3] A.. Gamp, 'On the preference of cold RF technology for the international linear collider', TESLA Report 200523, 2005.

[4] M. Champion, 'Design, performance and production of the FERMILAB TESLA RF input couplers', Proc. $18^{\text {th }}$ International Linear Accelerator Conference, pp 521-524, Geneva, 1996.

[5] W.-D. Möller,'High power Coupler for TESLA Test Facility', Proc. $9^{\text {th }}$ workshop on RF superconductivity, Santa fe, New Mexico, USA, 1999.
[6] D. Kostin, W.-D. Möller, 'Status and operating experience of the TTF coupler', Proc. $22^{\text {nd }}$ International Linear Accelerator Conference, pp 156-158, Lübeck, Germany, 2004.

[7] T. Garvey et al. 'The TESLA high power coupler program at Orsay', Proc. SRF20003, 8 -12 September 2003, Lübeck-Travemunde, Germany.

[8] T. Garvey, W.-D. Möller, 'The RF power coupler development program at LAL-Orsay and DESY-Hamburg for TESLA and the European X-FEL', Proc. International Congress On Optics and Opto-electronics, $28^{\text {th }}$ August$2^{\text {nd }}$ September 2005, Warsaw, Poland.

[9] H. Jenhani, 'Preparation and conditionnong of the TTF VUV-FEL power couplers', Proc. $12^{\text {th }}$ workshop on RF superconductivity, Ithaca, New York, USA, 2005.

[10] S. W. Van Sciver 'Helium cryogenics', International cryogeincs monograph series, Plenum Press, New York, 1986.

[11] Dohlus M., Kostin D.Möller W.-D.,'Tesla RF power Coupler Thermal Calculations', Proc. of LINAC 2004 Lübeck, Germany, 16 - 20 August 200.

[12]C. Benvenuti et al. 'Copper coatings for the main couplers of the LEP2 superconducting RF cavities', CERN LPE2 Note 94-21, 1994.

[13] J.P Thermeau et al. 'Cryogenic thermometers calibration facility for the LHC', CEC-ICMC'99, Montréal, Canada, July 1999.

[14] A. F. Clark et al., Cryogenics, august 1970, pp 295305.

[15] G. K. White 'Experimental techniques in low temperature physics', Monographs on the physics and chemistry of materials 43, Oxford University Press, Third Edition, 1978.

[16] X. Singer et al. 'Properties and structure of electrodeposited copper layers in parts of the TTF main coupler', Proc. SRF20003, 8 -12 September 2003, Lübeck-Travemunde, Germany. 